\title{
Increasing age and experience: are both protective against motorcycle injury? A case-control study
}

\author{
Bernadette Mullin, Rodney Jackson, John Langley, Robyn Norton
}

\begin{abstract}
Objectives-To assess the associations between age, experience, and motorcycle injury.

Setting-Motorcycle riding on nonresidential roads between 6 am and midnight over a three year period from February 1993 in Auckland, New Zealand. Methods-A population based casecontrol study was conducted. Cases were 490 motorcycle drivers involved in a crash and controls were 1518 drivers identified at random roadside surveys. Crash involvement was defined in terms of a motorcycle crash resulting in either a driver or pillion passenger being killed, hospitalised, or presenting to a public hospital emergency department with an injury severity score $\geqslant 5$.

Results-There was a strong and consistent relationship between increasing driver age and decreasing risk of moderate to fatal injury. In multivariate analyses, drivers older than 25 years had more than $50 \%$ lower risk than those aged from 15-19 years (odds ratio (OR) $0.46 ; 95 \%$ confidence interval (CI) 0.26 to 0.81 ). In univariate analyses, a protective effect from riding more than five years compared with less than two years was observed. However, this protection was not sustained when driver age and other potential confounding variables were included in the analyses. Familiarity with the specific motorcycle was the only experience measure associated with a strong protective effect $(\mathrm{OR}(\geqslant 10000 \mathrm{~km}$ experience) $0.52 ; 95 \%$ CI 0.35 to 0.79 ) in multivariate analyses.
\end{abstract}

Conclusions-Current licensing regulations should continue to emphasise the importance of increased age and might consider restrictions that favour experience with a specific motorcycle.

(Injury Prevention 2000;6:32-35)

Keywords: motorcycles; age; experience

Between 1990 and 2020, it is estimated that road traffic crashes will move from the ninth to the third largest cause of death and disability globally. ${ }^{1}$ Over $90 \%$ of this death and disability will occur in the developing world, in which a large proportion of vehicles are two or three wheeled. ${ }^{2}$ In many developed countries, motorcyclists suffer a disproportionate number of road traffic crashes. In New Zealand, for example, motorcycles account for fewer than $2 \%$ of kilometres driven, but $9 \%$ of reported injuries and $13 \%$ of fatalities from all road traffic crashes. ${ }^{3}$ Given the relative importance of injuries from motorcycle crashes, effective strategies are needed to reduce this injury burden.

Driver age and experience are used internationally as components of licensing restrictions aiming to reduce the injury burden from road traffic crashes. Increased age of the motorcycle driver has been strongly and consistently shown to protect against the risk of fatal and non-fatal injury from motorcycle crashes. ${ }^{4-18}$ However, while increasing experience has been widely reported as a protective factor for motorcycle injury,,$^{51213161719}$ few studies have considered the relationships between age and experience together. ${ }^{512} 16$

This paper reports the results of a casecontrol study in which associations were examined between age, different measures of road traffic experience, and risk of moderate to fatal injury resulting from a motorcycle crash.

\section{Subjects and methods}

The population from which study participants were selected included all motorcyclists riding on non-residential public roads in the Auckland region of New Zealand, between 6 am and midnight, over a three year period from February 1993 to February 1996. A motorcycle was defined using the International Classification of Diseases, ninth revision, clinical modification (1980) definition of a two wheeled vehicle. ${ }^{20}$ Because of the low traffic volumes on residential roads and between midnight and 6 am (less than $2 \%$ of riding $^{3}$ ), motorcyclists riding on these roads and at these times, were excluded. The Auckland region has a population of approximately 950000 people of whom 93\% live in urban Auckland (1991 census).

\section{SELECTION OF CASES}

Over the study period, all motorcycle drivers or pillion passengers who were killed, hospitalised, or presented within 24 hours of a crash to a public hospital emergency department with an injury severity score of $\geqslant 5$ were identified. Tricode, a personal computer injury coding software $^{21}$ was used to provide an objective measure of injury severity using text injury descriptions. To ensure comprehensive case finding, a number of methods were used, including reviewing emergency department attendance registers, hospital admission lists, the coroner's database, and police reported lists of fatal and injury motorcycle crashes. All motorcycle drivers involved in these incidents were then invited to participate in the study as cases. 
SELECTION OF CONTROLS

Controls were motorcycle drivers identified from 150 roadside survey sites. Each site was selected randomly, from a listing of all non-residential roads in the region, in proportion to the total length of the road. Each site was sampled over a 90 minute period, at three random times, during the study period and all motorcyclists passing the site were invited to participate in the study. This resulted in a random sample of motorcycle riding.

\section{DATA COLLECTION}

Case interviews were conducted face to face in hospital, or by telephone if they were discharged. For those who were killed, the next of kin was contacted after six weeks and asked to nominate a person for interview. All control motorcycles were photographed and if possible stopped for the driver to be breathalysed. Telephone details were obtained for a later interviewer administered questionnaire. For roadside survey sites on motorways, or those that were at times when it was too dangerous to stop motorcycles, controls were followed up via the motorcycle registration number and interviews conducted by telephone.

Both case and control drivers were administered identical questionnaires, except that details of exposures at the time of the crash among cases were substituted for exposures at the time of the survey for controls. Data were collected on a range of experience variables as well as age, gender, and other covariates. The experience variables included the total years of regular on and off-road riding and car driving; the frequency of on and off-road riding and car driving in the previous year; whether the driver had previously driven on the road before; and the total distance the driver had ridden on that motorcycle (familiarity).

The other covariates included socioeconomic status (assessed in terms of occupation), posted speed limit $(<100 \mathrm{~km}$ per hour $v 100$ $\mathrm{km}$ per hour), self reported speeding (riding more than $20 \mathrm{~km}$ per hour over the speed limit $v$ not), presence of a male or female pillion passenger, time of day and day of week riding, use of headlights, motorcycle cc rating, road conditions (wet $v$ dry), current licence status (full $v$ partial $v$ unlicensed), and self reported recent alcohol consumption (any consumption in last 12 hours $v$ none).

Ethical approval for the conduct of the study was obtained from the Northern Regional Health Authority ethics committee.

\section{STATISTICAL ANALYSIS}

Univariate and adjusted odds ratios were calculated using unconditional logistic regression in SAS. ${ }^{22}$ A comprehensive multivariate model was developed that included the exposures of interest as well as potentially important confounding variables identified from the literature, as proposed by Rothman. ${ }^{23}$

\section{Results}

There were 490 case motorcycle drivers identified (32 were fatally injured) with 60 pillion passengers. Interviews were completed for 463 drivers $(95 \%)$, including 35 completed by proxy respondents. There were 13 case drivers who refused to participate and 14 who could not be contacted. Telephone interviews were conducted with $63 \%$ of the interviewed case drivers.

There were 1518 control motorcyclists identified with 151 pillion passengers. Altogether $931(61 \%)$ were identified at sites where motorcyclists were stopped and 587 (39\%) from photograph only sites, such as motorways or wet roads. Interviews were completed for 1233 drivers $(81 \%)$, including nine completed by proxy respondents. The majority of drivers not interviewed could not be contacted, with only $3 \%$ actively refusing to participate. Telephone interviews were conducted with $96 \%$ of the interviewed control drivers.

In both groups, those aged 25 years or older comprised the largest age group, and $94 \%$ were male (table 1). High proportions $(>48 \%$ ) had been riding motorcycles and driving cars regularly for more than five years; more than $70 \%$ had driven a motorcycle three days a week or more in the previous year; high proportions $(>75 \%)$ had ridden more than $1000 \mathrm{~km}$ on the same (current) motorcycle; and more than $95 \%$ had previously ridden on the road where they crashed or were surveyed.

There was a strong and consistent relationship between increasing driver age and decreasing risk of moderate to fatal injury from a motorcycle crash (table 2). In multivariate analyses, drivers aged 25 years or older had more than a $50 \%$ lower risk than those aged from $15-19$ years (odds ratio (OR) 0.46 ; 95\% confidence interval (CI) 0.26 to 0.81 ). There was no evidence of any association between gender and risk.

Table 1 Distribution of age, gender, and measures of experience for cases and controls *

\begin{tabular}{lcl}
\hline & $\begin{array}{l}\text { No }(\%) \\
\text { controls }\end{array}$ & No (\%) cases \\
& & \\
\hline Age (years) & $132(10.6)$ & $87(18.3)$ \\
$15-19$ & $323(26.0)$ & $153(32.2)$ \\
$20-24$ & $786(63.3)$ & $235(49.5)$ \\
$25+$ & $72(5.8)$ & $27(5.7)$ \\
Gender & $1169(94.2)$ & $448(94.3)$ \\
Female & $197(16.1)$ & $97(21.4)$ \\
Male & $338(27.5)$ & $136(30.0)$ \\
Years regular on-road motorcycle riding & \\
$<2$ & $692(56.4)$ & $221(48.7)$ \\
$2-5$ & $174(14.6)$ & $85(18.9)$ \\
$>5$ & $219(18.4)$ & $104(23.1)$ \\
Years regular car driving & $799(67.0)$ & $261(58.0)$ \\
$<2$ & $130(10.5)$ & $60(13.1)$ \\
$2-5$ & $217(17.6)$ & $63(13.7)$ \\
$>5$ & $888(71.9)$ & $336(73.2)$ \\
On-road motorcycle riding in last year (days/week) \\
$<1$ \\
$1-2$ & $166(13.7)$ & $99(22.3)$ \\
$\geqslant 3$ & $478(39.3)$ & $179(40.3)$ \\
Familiarity with the specific motorcyle (km) & \\
$<1000$ & $571(47.0)$ & $166(37.4)$ \\
$1000-9999$ & $28(2.3)$ & $21(4.6)$ \\
$\geqslant 10$ 000 & $1204(97.7)$ & $438(95.4)$ \\
Familiarity with the road $\dagger$ & & \\
Never driven before & & \\
Driven before & & \\
& &
\end{tabular}

Totals may not add to $100 \%$ due to rounding.

${ }^{\star}$ Column totals may differ due to inclusion of data for cases and controls for whom completed interviews were not obtained and missing data from those who completed interviews.

†The road where the crash occurred or control was identified. 
Table 2 Unadjusted, age adjusted, and multivariate adjusted odds ratios (OR) and 95\% confidence intervals (95\% CI) of sustaining a motorcycle injury associated with age, gender, and experience

\begin{tabular}{|c|c|c|c|}
\hline & $\begin{array}{l}\text { Unadjusted OR } \\
\text { (95\% CI) }\end{array}$ & $\begin{array}{l}\text { Age adjusted OR } \\
(95 \% \mathrm{CI})\end{array}$ & $\begin{array}{l}\text { Multivariate adjusted } \\
\text { OR }(95 \% \text { CI })\end{array}$ \\
\hline \multicolumn{4}{|l|}{ Age (years) } \\
\hline $15-19$ & 1 & & 1 \\
\hline $20-24$ & $0.72(0.52$ to 1.00$)$ & & $0.69(0.43$ to 1.11$)$ \\
\hline $25+$ & $0.45(0.33$ to 0.62$)$ & & $0.46(0.26$ to 0.81$)$ \\
\hline \multicolumn{4}{|l|}{ Gender } \\
\hline Female & 1 & 1 & 1 \\
\hline Male & $1.04(0.66$ to 1.64$)$ & $1.03(0.65$ to 1.64$)$ & $0.90(0.51$ to 1.60$)$ \\
\hline \multicolumn{4}{|c|}{ Years regular on-road motorcycle riding } \\
\hline$<2$ & 1 & 1 & 1 \\
\hline $2-5$ & $0.82(0.60$ to 1.12$)$ & $0.97(0.70$ to 1.34$)$ & $1.10(0.73$ to 1.68$)$ \\
\hline$>5$ & $0.65(0.49$ to 0.86$)$ & $1.05(0.74$ to 1.51$)$ & $1.57(0.96$ to 2.58$)$ \\
\hline \multicolumn{4}{|l|}{ Years regular car driving } \\
\hline$<2$ & 1 & 1 & 1 \\
\hline $2-5$ & $0.97(0.68$ to 1.38$)$ & $1.01(0.70$ to 1.45$)$ & $0.94(0.61$ to 1.46$)$ \\
\hline$>5$ & $0.67(0.50$ to 0.90$)$ & $1.12(0.78$ to 1.62$)$ & $0.88(0.56$ to 1.38$)$ \\
\hline \multicolumn{4}{|c|}{ On-road motorcycle riding in last year (days/week) } \\
\hline$<1$ & 1 & 1 & 1 \\
\hline $1-2$ & $0.63(0.42$ to 0.95$)$ & $0.64(0.42$ to 0.98$)$ & $0.81(0.55$ to 1.19$)$ \\
\hline$\geqslant 3$ & $0.82(0.59$ to 1.14$)$ & $0.81(0.58$ to 1.13$)$ & $0.81(0.52$ to 1.27$)$ \\
\hline \multicolumn{4}{|c|}{ Familiarity with the specific motorcycle $(\mathrm{km})$} \\
\hline$<1000$ & 1 & 1 & 1 \\
\hline $1000-9999$ & $0.63(0.46$ to 0.85$)$ & $0.62(0.46$ to 0.84$)$ & $0.60(0.41$ to 0.88$)$ \\
\hline$\geqslant 10000$ & $0.49(0.36$ to 0.66$)$ & $0.54(0.40$ to 0.74$)$ & $0.52(0.35$ to 0.79$)$ \\
\hline \multicolumn{4}{|l|}{ Familiarity with the road } \\
\hline Never driven before & 1 & 1 & 1 \\
\hline Driven before & $0.49(0.27$ to 0.87$)$ & $0.55(0.31$ to 0.98$)$ & $1.49(0.69$ to 3.22$)$ \\
\hline
\end{tabular}

Variables included were age, gender, years of regular motorcycle and other vehicle driving, socioeconomic status, posted speed limit, self reported speeding, familiarity with the motorcycle and the road, presence of a male or female pillion passenger, riding frequency in the last year, time of day and day of week riding, use of headlight, motorcycle cc rating, road conditions, licence status, self reported recent alcohol consumption.

The unadjusted odds ratio for riding more than five years compared with less than two years showed a strong protective effect (OR $0.65 ; 95 \%$ CI 0.49 to 0.86$)$. However there was no evidence of a protective effect after adjusting for age (OR 1.05; 95\% CI 0.78 to 1.51) and other potential confounders (OR 1.57 ; $95 \%$ : CI 0.96 to 2.58 ).

Familiarity with the motorcycle was the only measure of experience associated with a strong protective effect in multivariate analyses. Drivers who had driven their current motorcycle $10000 \mathrm{~km}$ or more had a $48 \%$ reduced risk (95\% CI 0.35 to 0.79 ) compared with those who had driven their motorcycle less than 1000 $\mathrm{km}$. There was no evidence of any clear protective effect with increasing years of regular car driving, riding frequently in the previous year, or being familiar with the road. Other variables that were also investigated and showed no evidence of any association with risk were off-road motorcycle riding and the frequency of driving another vehicle in the previous year.

\section{Discussion}

This study confirms the strong association found previously between increasing age and lower risk of motorcycle injury, ${ }^{4-18}$ with drivers aged 25 years or over having less than half the risk of those aged under 20 years. However, there is little evidence that increasing years of regular motorcycle or car driving reduce the risk of moderate to fatal injury from a motorcycle crash, once the age of the driver and other factors are also considered. Familiarity with the specific motorcycle is the only experience measure associated with a strong protective effect.
Many previous studies of experience have reported only univariate results or controlled for a limited range of potential confounding variables in their analyses ${ }^{71317} 18$ and not surprisingly, their findings are consistent with the unadjusted results from this study. Of the four previous studies that have examined both age and experience, three have reported a protective effect of increasing experience. However, biases in the selection of study participants, the measures of exposure and the outcome measures, may account for these findings. A cross sectional study by Bragg et al, of over 7000 randomly selected drivers from Ontario, reported that motorcyclists licensed less than two years were at increased risk of injury. ${ }^{5}$ Additionally, the response rate in this study was only $31 \%$. McKnight and Robinson followed a cohort of 12000 newly licensed drivers in Pennsylvania for one year. ${ }^{12}$ After controlling for the age of the motorcyclist, they reported that those with less than two years' experience had two to four times as many crashes. A cross sectional study by Taylor and Lockwood analysed data from a random sample of 10000 registered owners of motorcycles in the United Kingdom and reported that the frequency of all self reported crashes (including minor spills) decreased rapidly with increasing experience. ${ }^{16}$ One study, by Rutter and Quine, who further studied 4000 of the original Taylor and Lockwood cohort, reported that young drivers were at increased risk of a crash independent of experience. ${ }^{18}$ However this study had a $13 \%$ response rate and included all minor spills.

The current study has several major strengths. The control population was a random sample of motorcycle riding rather than a sample of motorcyclists. Thus it was unnecessary to control for current exposure to motorcycle riding (distance ridden or time spent riding) as confounding variables. Selection bias was also low with comprehensive case finding procedures, and high response rates. While non-fatal cases were limited to motorcyclists presenting to public hospitals, a pilot study had shown that fewer than $3 \%$ of those presenting to an emergency department in the private sector meet the injury criteria, all with an injury severity score of only 5 . Additionally, though the study population was limited to motorcyclists on non-residential roads between $6 \mathrm{am}$ and midnight, this represents the largest proportion of all motorcycle riding. Information bias due to systematic differences in the method of obtaining information between the case and control populations or because of recall bias among cases was minimised by using standardised interviews and a reference point for acute exposures (crash or survey). Although it is possible that such biases may have been introduced, it seems unlikely that they could explain entirely the protective effects associated with increasing age and familiarity with the specific motorcycle.

In conclusion, there is strong and consistent evidence that young motorcyclists, especially those under 20 years, are at an increased risk of injury compared with older riders and good evidence to suggest that familiarity with a spe- 
cific motorcycle is protective. However the evidence is neither strong nor consistent for the protective effects of other aspects of driver experience. These findings suggest that licensing policies should continue to place emphasis on the age of the driver. They also suggest that policies might be developed that maximise young drivers' familiarity with a particular motorcycle as part of the licensing process. However, as there is little evidence to support the protective effects associated with other experience factors, including previous car driving, regulations based on these other experience measures might well be reviewed.

We thank the participating motorcyclists; Angela Hursthouse, Kevin Sherlock, Mark McLauchlan, and other staff at the Injury Kevin Sherlock, Mark McLauchlan, and other staff at the Injury Prevention Research Centre; staff at participating

The Health Research Council of New Zealand (HRC) and the Accident Rehabilitation and Compensation Insurance Corporation (ACC) jointly funded this study. Dr Mullin was the recipient of a HRC Training Fellowship. The Injury Prevention Research Centre and the Injury Prevention Research Unit are both jointly funded by the HRC and ACC.

1 Ad Hoc Committee on Health Research Relating to Future Intervention Options. Investing in health research and development. (Document TDR/Gen/96.1.) Geneva: World Health Organisation, 1996

2 TRL Overseas Centre and Ross Silcock Ltd. Road safety guidelines for the Asia and Pacific region. Manila: Asian Development Bank, 1997.

3 Land Transport Division. New Zealand Ministry of Transport. New Zealand household travel survey, Fuly 1989-Fune 1990. Traffic research report 43. Wellington: Ministry of Transport, 1992.

4 Kraus JF, Riggins RS, Franti CE. Some epidemiological features of motorcycle collision injuries. I. Introduction, methods and factors associated with incidence. $A m \mathscr{f}$

5 Bragg BW, Dawson NE, Jonah BA. Profile of the accident Bragg BW, Dawson NE, Jonah BA. Profile of the accident involved motorcyclist in Canada. Proceedings of the international motorcycle safety conference. Washington, 1980.
Washington: International Motorcycle Safety Conference, Washingt 1980.

6 Jonah BA, Dawson NE, Bragg BW. Evaluation of the Canada Safety Council's motorcycle training program. International Motorcycle Safety Conference. Washington, 1980. Washington: International Motorcycle Safety Conference, 1980 .
7 Hurt HH, Ouellet JV, Thom DR. Motorcycle accident cause factors and identification of countermeasures. Volume 1: technial report. Report for the US Department of Transportation, National Highway Traffic Safety Administration. Washington, DC: National Highway Traffic Safety Adminstration, 1981 .

8 Jonah BA, Dawson NE, Bragg BW. Predicting accident involvement with the motorcycle operator skill test. Accid Anal Prev 1981;13:307-18.

9 Hobbs C, Galer I, Stroud P. The characteristics and attitudes of motorcyclists: a national survey. Research report 51 . Crowthorne, UK: Transport and Road Research Laboratory, Department of Transport, 1986.

10 Broughton J. The relation between motorcycle size and accident risk. Research report 169. Crowthorne, UK: Transport and Road Research Laboratory, Department of Transport, 1988 .

11 Namradan F, Elton RA. A study of reported injury accidents among novice riders in a Scottish region. Accid Anal Prev 1988;20:117-21.

12 McKnight AJ, Robinson AR. The involvement of age and experience in motorcycle accidents. Proceedings of international motorcycle safety conference. Orlando, Florida, 1990. Volume 1. Orlando, Florida: International Motorcycle Safety Conference, 1990 .

13 McLean AJ, Chen PCY, Wong TW, et al. Comparative studies of motorcycle accidents. Research report 2/90. Adelaide: WHO Collaborating Centre in the Prevention and Control of Road Traffic Accidents, 1990.

14 Schulz U. Factors affecting different kinds of motorcycle accidents. Proceedings of international motorcycle safety conference. Orlando, Florida, 1990. Volume 1. Orlando, Florida: International Motorcycle Safety Conference, 1990.

15 Rockwell TH, Kiger SM, Carnot MJ. An evaluation of the Ohio motorcyclist enrichment program. Phase II. Initial assessOhio motorcyclist enrichment program. Phase II. Initial assessment report.

16 Taylor MC, Lockwood CR. Factors affecting the accident liability of motorcyclists - multivariate analysis of survey data. Research report 270. Crowthorne, UK: Transport and Road Research Laboratory, Department of Transport, 1990.

17 Wong T, Lee J, Phoon W, et al. Driving experience and the risk of traffic accident among motorcyclists. Soc Sci Med 1990;30:639-40.

18 Rutter D, Quine L. Age and experience in motorcycling safety. Accid Anal Prev 1996;28:15-21.

19 Vaughan RG, Pettigrew K, Lukin J. Motorcycle crashes: a level two study. New South Wales: Traffic Accident Research Unit, Department of Motor Transport, 1977.

20 World Health Organisation. International classification of diseases, 9th revision. Clinical modification. (ICD9.CM.) Ann Arbor, Michigan: Edwards Brothers Inc, 1980

21 Tri-analytics Inc. Tricode injury coding software. Bel-Air, MD: Tri-analytics Inc, 1995.

22 SAS Institute Inc. SAS procedures guide. Release 6.03 edition. Cary, NC: SAS Institute Inc, 1988.

23 Rothman KJ. Modern epidemiology. Boston/Toronto: Little, Brown, 1986.

Editorial Board Member: brief biography

LEONORA OLSON

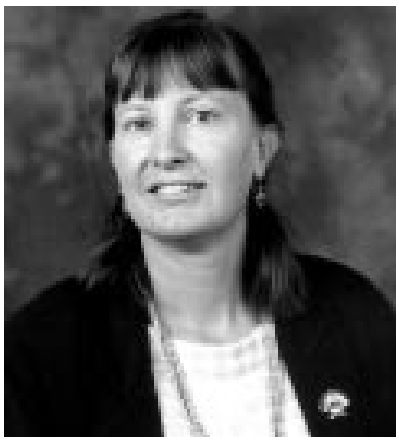

Leonora Olson, MA, is the Director of the Intermountain Injury Control Research Center located at the University of Utah Department of Pediatrics and Research Assistant Professor of Pediatrics at the University of Utah. She is the former chairperson of the Injury Control and Emergency Health Services Section of the American Public Health Association.

She received her master's degree in anthropology at the University of New Mexico in 1988. Her research interests include motor vehicle injuries, suicide, firearms, and intimate partner violence. 